This is the final peer-reviewed accepted manuscript of:
Martinez, Ana Karine; Soriano, Jose Miguel; TUBEROSA, ROBERTO; Koumproglou, Rachil; Jahrmann, Torben;
Salvi, Silvio
"Yield QTLome distribution correlates with gene density in maize"
which has been published in final form in PLANT SCIENCE 2016, V. 242, P. 300-309
The final published version is available online at:
http://dx.doi.org/10.1016\%2Fj.plantsci.2015.09.022

(C) 2016 Elsevier. This manuscript version is made available under the Creative Commons Attribution-NonCommercial-NoDerivs (CC BY-NC-ND) 4.0 International License (http://creativecommons.org/licenses/by-nc-nd/4.0/) 


\section{Yield QTLome distribution correlates with gene density in maize}

2

3 Ana Karine Martinez ${ }^{1}$, Jose Miguel Soriano ${ }^{1,2}$, Roberto Tuberosa ${ }^{1}$, Rachil Koumproglou ${ }^{3}$, Torben

$4 \quad$ Jahrmann $^{3}$, Silvio Salvi ${ }^{1}$

5

$6{ }^{1}$ Department of Agricultural Sciences, University of Bologna, Viale Fanin 44, 40127 Bologna, Italy

$7 \quad 2$ Field Crops Programme, IRTA (Institute for Food and Agricultural Research and Technology),

$8 \quad 25198$ Lleida, Spain

$9 \quad{ }^{3}$ Semillas Fitó, Selva de Mar 111, 08019 Barcelona, Spain

10

11 AKM and JMS contributed equally to this work

12

13 Corresponding author: silvio.salvi@unibo.it

14 


\section{ABSTRACT}

The genetic control of yield and related traits in maize has been addressed by many quantitative trait locus (QTL) studies, which have produced a wealth of QTL information, also known as QTLome. In this study, we assembled a yield QTLome database and carried out QTL meta-analysis based on 44 published studies, representing 32 independent mapping populations and 49 parental lines. A total of 808 unique QTLs were condensed to 84 meta-QTLs and were projected on the 10 maize chromosomes. Seventy-four percent of QTLs showed a proportion of phenotypic variance explained (PVE) smaller than 10\% confirming the high genetic complexity of grain yield. Yield QTLome projection on the genetic map suggested pericentromeric enrichment of QTLs. Conversely, pericentromeric depletion of QTLs was observed when the physical map was considered, suggesting gene density as the main driver of yield QTL distribution on chromosomes. Dominant and overdominant yield QTLs did not cluster differently from additive effect QTLs.

\section{Keywords}

Heterosis; Meta-analysis; QTL; QTLome; yield; Zea mays

\section{Introduction}

Progress in molecular biology and genomics platform allows us to identify the quantitative trait loci (QTL) that govern the expression of yield and other important agronomic traits, hence providing unprecedented opportunities to enhance the effectiveness of selection targeting the key loci via genomics-assisted breeding [1-4]. The number of mapped QTLs for a given trait and species, collectively known as QTLome [5] is growing at an impressive pace, prompting increased efforts in the synthesis and interpretation of QTL information.

In maize, grain yield is the most important and genetically complex trait and is generally modelled as controlled by a large number of small effect QTLs, in the contexts of both phenotypic and markerassisted selection $[6,7,8]$. While breeding has certainly succeeded in improving grain yield in maize during the last century, maintaining the same rate of improvement will be increasingly more difficult due to more extreme climatic conditions and the need to adopt new cropping systems requiring reduced inputs [9]. For these reasons, a better understanding of the grain yield QTLome (in terms of number of QTLs, their map position, size and type of genetic effects and interactions) remains a priority in maize breeding. 
One way to synthesize QTL information is by QTL meta-analysis [10,11] which allows one to identify the regions of the genome that more frequently govern trait variation and to narrow down the confidence intervals of QTLs by leveraging existing information. In maize, MetaQTLs (MQTLs) were described for flowering time [12,13], leaf architecture [14], grain moisture [15] and ear rot resistance [16]. Hao et al. [17] used meta-analysis to identify candidate genes potentially involved in drought tolerance networks. Meta-analysis was also applied to yield and yield components QTLs $[18,19,20]$. By collecting QTL [21,22] and transcriptomic [23] data from multiple studies, a predominant centromeric location of heterotic QTLs was observed.

This study reports the results of the largest MQTL analysis so far conducted for yield and yield components in maize. QTLs were projected on the genetic and physical maps and utilized to compute MQTLs. Our main objectives were to produce an informed repository of yield QTL information in maize and to search for patterns of QTL distribution on chromosomes, with particular attention to QTLs involved in yield heterosis.

\section{Materials and Methods}

\subsection{Bibliographic collection and construction of a maize yield QTLome database}

Literature was retrieved from Web of Science (Thomson Reuters ${ }^{\mathrm{TM}}$ ) (http://apps.webofknowledge.com) using the keywords 'maize yield QTL' which eventually identified 44 manuscripts published from 1992 to 2014. While papers presented QTL data for multiple traits, we only considered yield and yield components traits which were classified in eight main categories (Table 1). A summary of the QTL studies is reported in Table 2.

The yield QTLome database included information on: parents of the cross, type of cross, number of progenies, name of QTLs, trait, LOD score, proportion of phenotypic variance explained (PVE) by each QTL, QTL position on the authors' linkage map in terms of LOD peak and QTL supporting or confidence interval (CI) (Supplementary Material 1). In studies reporting multi-environment results, only QTLs from the overall analysis were considered; alternatively, if two QTLs for the same trait were reported in two experiments (eg. two different water regimes) in the same study (ie. in the same publication), and their map positions corresponded, they were considered as the same QTL and were included in our QTL database as one.

For each QTL, flanking molecular markers with their genetic position in the original map and with the highly saturated maize map 'Genetic' used as a reference map and available at 
http://www.maizegdb.org/complete_map?id=1203637, were searched and recorded. In order to avoid heterogeneity in definition of $C I$ across studies, 95\% CI values were estimated using the approach described by [66] and extended by [67] according to the population type: $C I=163 /\left(N^{*} R^{2}\right)$ for recombinant inbred line (RIL) progenies, and $C I=530 /\left(N^{*} R^{2}\right)$ for the rest of non-RIL progenies (i.e. $\mathrm{F}_{2}, \mathrm{BC}, \mathrm{TC}$ ), where $N$ is the size of the population and $R^{2}$ is the proportion of variance explained by the QTLs. Estimated CI values were utilized for QTL projection (Supplementary Material 1).

When available, the degree of dominance (often indicated as gene action) for each QTL was recorded as provided by the authors. More specifically, QTLs were declared as heterotic QTLs (HQ) when gene action was reported as dominant $(\mathrm{D}$, with dominant effect/additive effect $>0.8)$ or overdominant (OD, with $d / a>1)$. QTL were declared as additive (AQ) when gene action was reported as additive or partially dominant $(0<d / a<0.8)$. When not available, the degree of dominance was attributed on the basis of the type of experimental population, as follows: QTLs identified in RIL populations were considered as AQ; QTLs identified in mapping populations evaluated as testcrosses were classified as potentially heterotic QTLs (PHQ).

\subsection{QTL projection and meta-analysis}

QTLs were projected onto the 'Genetic' maize reference map available at http://www.maizegdb.org/complete_map?id=1203637 (see also [68]), using the software Biomercator v4.1 (http://moulon.inra.fr) [11,69]. The frequency (probability) of identification of QTL for every cM position in the 'Genetic' map was estimated following the approach described as 'QTL-overview index' [12]. Meta-analysis was carried out using BioMercator v. 4.1. The input file for BioMercator is provided as Supplementary Material 2.

For $n$ individual QTLs, BioMercator tests the most likely assumption between 1, 2, 3, 4 and $n$ underlying QTLs. Decision rules are based on an Akaike-type criterion (AIC) and the one with the lowest AIC value was considered the best fit. Consensus QTL from the optimum model is regarded as meta-QTL (MQTL). In order to study the QTL distribution based on physical distances QTLs were projected onto the B73 RefGen_v2 reference genome [70] (http://www.maizegdb.org/). Additionally, variation of QTL density across the maize genome was studied by counting QTLs on each 20-cM bin (roughly equivalent to $1 / 100$ of the genetic map) and on each $25-\mathrm{Mb}$ bin (again roughly equivalent to 1/100 of maize physical map), starting from the centromeric region of each chromosome (ie. the middle point of a centromere interval was considered as position 0). A QTL was assigned to a bin based on its LOD peak as reported in original studies. Centromeres positions were obtained from the http://www.maizegdb.org/ and from [71, 72]. Gene density distribution was determined from the 
maize genome sequence B73RefGen_v2 available at http://www.maizegdb.org/. QTLs, MQTLs and overview index were visually represented using CIRCOS [73].

\section{Results}

\subsection{Main features of QTL mapping experiments in maize}

Our survey covered 44 studies which reported QTLs for yield and yield components in maize, based on biparental populations and published from 1992 to 2014 (Table 2). The studies covered 32 different experimental crosses, which utilized 47 inbred lines as parents, the most popular being B73 and Mo17 (six and five crosses, respectively). The most common cross types were $\mathrm{F}_{2: 3}$ or $\mathrm{F}_{2: 4}$ evaluated per se, RIL per se and $\mathrm{F}_{2: 3}$ or $\mathrm{F}_{2: 4}$ evaluated as testcross/backcross (14, eight and seven populations, respectively; Table 2).

Although in many cases the original papers reported on QTLs for multiple morpho-physiological traits, we focused our survey on QTLs for grain yield (GY) and seven additional grain yield components of common interest in maize breeding (Table 1). The QTL database eventually included 808 unique QTLs. The number of QTLs per trait ranged from 23 to 253 (Ear Number and GY, respectively; Supplementary Material 3). The average number of QTL per study was 7.2 for GY, while it ranged between 4.6 and 7.5 for component traits (for Ear Number and Kernel Weight, respectively; Supplementary Material 3).

The frequency distribution for the proportion of phenotypic variance explained (PVE) by single QTLs followed a truncated (on minor values) L-shape with the majority of the QTLs showing low PVE values (74\% of the QTLs with PVE $<0.1$. Supplementary Material 4). The shape of the distribution did not differ between GY and GY components (Supplementary Material 4) and/or between heterotic and additive QTLs (not shown).

The number of GY (and other traits) QTLs per study did not correlate with population dimension (Supplementary Material 5).

\subsection{QTL distribution on chromosomes}

As evidenced in Figs. 1A-B, yield QTLs were evenly distributed among the ten chromosomes as also confirmed by the very high correlation $(r=0.94 ; \mathrm{P}<0.01)$ between number of QTLs and chromosome length. For example, chrs. 6 and 1, the shortest and the longest, respectively, carried the lowest and the highest number of QTLs (61 and 144, respectively). 
The projection of all QTLs on the maize genetic reference map showed a statistically significant clustering of QTLs at centromeric and pericentromeric regions (Fig. 1A, Fig. 2A). A 20-cM interval spanning from -10 to $+10 \mathrm{cM}$ from the centromere and representing approx. $10 \%$ of an average chromosome included $18 \%$ of all QTLs (Fig. 2A.). Mid-chromosome arm bins such as those around -60 and $+60 \mathrm{cM}$ from centromeres included significantly fewer QTLs (8 and $12 \%$ QTLs. $\mathrm{P}<0.01, \chi^{2}$ distribution), and increasingly so at subtelomeric bins (Fig. 2A). No difference in distribution was observed when the full 808 QTL set was subdivided in QTLs for GY and QTLs for GY component traits (not shown).

A different distribution pattern was observed when QTLs were projected on the maize reference physical map (Fig. 1B, Fig. 2B). On the physical map (Fig. 1B), QTLs appeared as almost evenly distributed with no sign of centromeric clustering (with the exception of chr. 9). When QTL distribution was tested by assigning QTLs to chromosome regions based on the map position of their QTL peaks, all the centromeric and pericentromeric 25-Mb bins were depleted of QTLs. For example, the 25-Mb bins spanning the centromeres had on average just 7\% of the QTLs while telomeric bins at -75 or at $+75 \mathrm{Mb}$ distance from centromere each gathered approx. $18 \%$ of the QTLs each $(\mathrm{P}<0.01$, $\chi^{2}$ distribution. Fig. 2B).

Prompted by the above-described QTL distribution on chromosomes, we tested the correlation between yield QTL density and gene density per 25-Mb bin starting from the centromere. QTL and gene densities showed a highly significant correlation (Pearson $r=0.41, P<0.01$ ).

Based on QTL-overview index the chromosome bins with the highest frequency of QTLs were 1.06, 2.04, 5.05, 8.05, 9.03 and 10.06. Conversely, bins 3.07-09 and 5.07-08 appeared depleted in QTLs based on both genetic and physical projections. Small regions with strikingly low QTL density were observed both on the genetic and physical projections at bins 1.04 (approx. $50 \mathrm{Mb}$ ), 1.09 (approx. $255 \mathrm{Mb}$ ), 4.03 (approx.. $20 \mathrm{Mb}$ ) and 6.06 (approx.. $140 \mathrm{Mb}$ ). It should be noted that subtelomeric bins were not considered in these comparisons since these chromosome portions were likely underrepresented in the original linkage maps, especially in the earlier QTL mapping studies.

Finally we found no difference in the average QTL PVE values computed considering all QTLs mapping within each 20-cM bin from centromeres to telomeres (Supplementary Material 6).

\subsection{Distribution patterns of heterotic QTLs}

Based on population types and QTL gene action as reported on original studies, our collection included 206 (26\%) heterotic QTLs, 136 (17\%) potentially heterotic QTLs and 466 (58\%) additive QTLs. The highest proportions (67, 69 and 73\%) of heterotic QTLs over the total number of QTLs 
were observed for GY, Ear Length and Kernel Number, respectively, whereas the lowest proportion (24\%) was observed for Ear Row Number (Supplementary Material 3).

Heterotic QTLs mapped unevenly on all chromosomes. Chrs. 1, 8 and 9 showed 35, 32 and 33\% of heterotic QTLs, respectively, while chrs. 5, 4 and 7 showed 16, 18 and 19\%, respectively. Like the global set of QTLs, heterotic and potentially heterotic QTLs clustered at pericentromeric regions when projected on the genetic map (Fig. 2C) whereas an opposite pattern of higher density at subtelomeric regions was apparent when physical distance was considered (Fig. 2D). In order to reduce the bias and noise potentially present in the latter two distributions, GY-only (ie. without grain yield components) heterotic and additive QTLs were extracted and their distributions compared (Fig. 2E-F). Again, no significant difference between heterotic and additive QTLs was observed in terms of distribution pattern along genetic maps $\left(\chi^{2}=7.97, \mathrm{df}=8, P>0.1\right)$. While the two distributions on physical maps differed $\left(\chi^{2}=22.7, \mathrm{df}=8, P<0.05\right)$, the patterns revealed no obvious trend (eg. higher concentration of HQ vs. AQ at subtelomeric or at pericentromeric regions).

\subsection{Meta-QTL analysis}

Among $808 \mathrm{GY}$ and grain yield-related traits QTLs projected onto the reference 'Genetic' map, 610 QTLs were grouped into 84 meta-QTLs (MQTLs) (Supplementary Material 7). The remaining 198 QTLs were not assigned to any MQTL. Confidence intervals (CI) of the MQTLs were narrower than the mean of the respective original QTL CIs, on average up to 7 fold. MQTLs CI ranged from 0.1 (Seven MQTL with CI $<1 \mathrm{cM}$ ) to $8.78 \mathrm{cM}$, with an average of $3.1 \mathrm{cM}$. MQTLs mapped on all ten chromosomes, and like single QTLs, suffered from an enlarged CI when mapped at pericentromeric regions (Figs. 1A-B). MQTL positions reported in this study were compared with those reported in Wang et al. [20] (Supplementary Material 8). MQTLs were also tentatively compared with those reported in Semagn et al [19], although in this case a different map was used for MQTL projection. Based on overlapping MQTL CIs, 19 MQTLs are common with those reported by Wang et al. [20] ranging from one MQTL on chr. 3 and 5 to six MQTLs on chr. 4 (Supplementary Material 8). Twenty-six MQTLs are putatively shared with those reported by Semagn et al. [19] involving yield and related traits and ranging from one MQTL on chrs. 1 and 10 to five on chr. 9 (data not shown).

\section{Discussion}

\subsection{Gene density appears as the main driver of QTL density}


Based on current knowledge, QTLs result from the genetic segregation of sequence polymorphisms at functional elements, such as regulatory sequences upstream of genes and/or coding sequences [74,5]. Therefore, it is expected that QTL density on a genetic map is driven by gene density, polymorphism rate at functional sites in genic regions and by frequency of recombination. Our results showed for the first time that the distribution pattern of QTLs on chromosomes differs strongly between genetic and physical maps. While QTLs appeared to more densely map near centromeres on genetic maps, they showed higher density at subtelomeric regions on physical maps. In maize and other species, gene density is higher at subtelomeric regions and lower at pericentromeric regions [75]. A similar distribution pattern was shown in this study for QTL density, which correlated well ( $r=0.41$ ) with gene density. Interestingly, a recent investigation on crossover density distribution in maize [76] reported a tight correlation between crossover distribution, gene density and cytosine methylation. Additionally, the authors showed that recombination is strongly 232 suppressed in $\sim 100 \mathrm{Mb}$ interval encompassing the centromere [76], which corresponds well to the low QTL-density region observed in our study (Fig. 2B).

Testing for the presence of correlation between QTL density and sequence polymorphism rate appears less straightforward. In maize, sequence polymorphism rate expressed as nucleotide diversity $(\pi)$ drops significantly in the proximity (approx. $+/-10 \mathrm{Mb}$ ) of centromere regions only, and levels off 237 in the rest of the chromosomes length [77]. Estimates of molecular polymorphism (e.g. SNP) are 238 available across the maize genome for coding, coding-enriched or low-complexity regions only [72, 239 79], however they are expected to be gene-density driven and not expected to represent well 240 regulatory sequence polymorphism (e.g. allelic difference at promoters or enhancers) often 241 interspersed with transposons, which have been shown to underpin many QTLs [80]. Finally, given 242 that recombination is a main factor in enabling purifying selection [81], regions with reduced 243 recombination are expected to show a higher rate of deleterious variants (as shown in [76]), which 244 should translate into higher rates of functionally different QTL alleles, and eventually higher QTL 245 density. However, this is exactly the opposite of what we observed. One possible explanation is that 246 the reduced gene density in low recombination regions completely overturns the impact of higher 247 rates of deleterious variants on QTL density. Following the observations above, we have not 248 attempted to correlate QTLs and sequence polymorphism densities as we felt it to be too speculative. 249 Taken all these observations together, and accounting for the cline of recombination rate along 250 chromosomes, gene density appears to be a strong driver of QTL density on chromosomes. 
Our study included 206 heterotic QTLs for GY and grain yield components. For GY, the majority of QTLs (67\%) showed dominant or overdominant types of gene action, accordingly with previous observations [21,22]. The same two former reports [21,22] found a higher-than-expected clustering of heterotic QTLs at low-recombining pericentromeric regions. Thiemann et al. [23] complemented the results of Schon et al. [22] by showing that pericentromeric regions are enriched in genes with an expression pattern correlated with grain yield heterosis. These results appear to support the dominance hypothesis for heterosis, in this case driven by the low recombination rate at pericentromeric regions which should maintain higher allelic diversity at different heterotic loci linked in the repulsion phase $[22,82,83]$. Our results confirmed the clustering of heterotic QTLs at centromeres on the genetic map. Additionally, we found little or no evidence for a distribution pattern difference between heterotic and additive QTLs, in line with what was reported by Larièpe et al. [22] based on a smaller set of QTLs. Indeed, the low recombination rate at pericentromeric regions can favour the fixation of both repulsion-phase and coupling-phase allelic combinations between breeding pools, potentially leading to large effect QTLs, both 'heterotic' and 'additive' [22,82]. In contrast with this last hypothesis, however, our data also showed that the average QTL PVE values did not significantly change across chromosome regions (Supplementary Material 6). In conclusions, additional investigations are required to test these hypotheses by also considering the higher frequency of deleterious variants expected at centromeres (see previous paragraph).

\subsection{Additional observations on QTL distribution pattern}

Some less obvious features were observed in the QTL projections on genetic and physical maps (Figs. 1A-B). Of the six chromosome bins $(1.06,2.04,5.05,8.05,9.03$ and 10.06) characterized by high QTL density peaks, four were located at pericentromeric regions, leaving little room for speculation on correspondence with genes. However, two peaks (at bins 8.05, and 10.06) were not in proximity of centromeres. The peak at bin 8.05 corresponds well with the $V g t 1 / \operatorname{Vgt} 2$ region [84, 85] and bin 10.06 peak corresponds with a previously reported flowering time MQTL [12]. Meta-analysis identified MQTLs in the same positions (MQTL62-63 and MQTL78-79) (Table 3). These QTLs are among the strongest and most frequently found flowering time QTLs in maize and this correspondence suggests that their alleles have remarkable effects on grain yield.

It is tempting to link regions with reduced QTL density with chromosome regions which have undergone selective sweep. Unfortunately, the generally low precision of QTL maps, as compared to the kb- to Mb-range typical of selective sweep studies (e.g. [86,87]) and the remarkably low linkage 
disequilibrium in maize precluded meaningful comparisons. However, two chromosome regions identified in our study with a strikingly low level of QTL density (on chr. 1, at approx. $50 \mathrm{Mb}$ and on chr. 6, at approx. $130 \mathrm{Mb}$ ) may correspond to regions characterized by high identity-by-descent of the parental lines and by a relatively high recombination rate, as identified in the maize HapMap2 study (Supp. Fig. 9 in [77]).

\subsection{Meta-analysis and breeding implications}

Meta-analysis allowed for a remarkable simplification of the yield QTLome since the initial number of QTLs was reduced by $65 \%$ of the initial number of QTLs and the average QTL confidence interval was reduced 7-fold. However, no clear trend of MQTL distribution on chromosomes was evidenced. MQTL positions reported in this study have some congruency with other results recently published. Nineteen MQTLs are shared with [20] using the same reference map for QTL projection (Supplementary Material 7). In three of these MQTLs (MQTL7, MQTL10 and MQTL36) maize orthologs of rice yield genes were identified [20]. Additionally, 27 MQTLs are putatively shared with [19]. In this case, we can only speculate on relative map positions since the map developed by [19] was based on SNPs and shares no markers with the reference map 'Genetic' used in the present study. On chromosome 4, our MQTL31 corresponds to the position where Bommert et al. [88] found a QTL for Ear Row Number containing the candidate gene FASCIATED2 (FEA2).

It should be noted that QTL meta-analysis could gain power and precision if raw genotypic and phenotypic data from published QTL experiments were made available [5].

In a breeding perspective, accordingly to Löffler et al. [89], three criteria must be taken into consideration when deploying MQTL information: i) MQTLs should have small supporting intervals, ii) a MQTL should include a high number of initial QTLs and iii) the initial QTLs should be characterized by high PVE. The identification of MQTL-linked markers will help to prioritize QTL/loci for marker-assisted breeding programs and for QTL cloning [90], thus possibly positively influencing the improvement of crop models [91].

\section{Conclusions}

The analysis of a large set of QTL data enables to verify emerging properties typically precluded by smaller datasets. In this study, we verified for the first time whether yield QTLs, on a large scale, are characterized by specific mapping patterns on maize chromosomes. When QTLs were projected 
321 on the genetic map, clustering at pericentromeric regions was identified as a consequence of the much 322 lower recombination frequency at the same regions. Conversely, when QTLs were projected on the 323 physical maps and QTL peaks rather than confidence interval were considered, low QTL density was 324 observed at centromeric regions and high QTL density at subtelomeric regions. QTL density was 325 found to be significantly associated with gene density. Despite previous preliminary indications, our 326 study did not evidence difference in density pattern of heterotic and additive effect QTLs across 327 chromosomes. However, the inherent statistical noise of QTL data may have precluded us from 328 revealing the existence of distinguished mapping pattern of heterotic QTLs.

329 Although our study represents the largest meta- analysis so far carried out in maize, it only 330 includes a small fraction of all QTL information published in maize. Further extension of the maize 331 yield QTLome information through the inclusion of QTLs from genome-wide association studies will 332 improve our understanding of the molecular and evolutionary basis of this key quantitative trait, an 333 important prerequisite for enhancing the effectiveness of maize breeding.

\section{Acknowledgements}




\section{References}

[1] R.K. Varshney, R. Terauchi, S.R. McCouch, Harvesting the promising fruits of genomics: applying genome sequencing technologies to crop breeding, PLoS Biol 12 (2014) e1001883.

[2] J.G. Wallace, S.J. Larsson, E.S. Buckler, Entering the second century of maize quantitative genetics, Heredity 112 (2014) 30-38.

[3] T.F.C. Mackay, E.A. Stone, J.F. Ayroles, The genetics of quantitative traits: challenges and prospects, Nat. Rev. Genet. 10 (2009) 565-577.

[4] M. Tester, P. Langridge, Breeding technologies to increase crop production in a changing world, Science 327 (2010) 818-822.

[5] S. Salvi, R. Tuberosa, The crop QTLome comes of age, Curr. Opin. Biotech. 32 (2015) 179-185.

[6] D.N. Duvick, Genetic progress in yield of United States maize (Zea mays L.), Maydica 50 (2005)193-202.

[7] R. Bernardo, Molecular markers and selection for complex traits in plants: learning from the last 20 years, Crop Sci. 48 (2008) 1649-1664.

[8] A.R. Hallauer, M.J. Carena, J.B. Miranda Filho, Testers and combining ability, Springer, New York 2010, pp. 383-42.

[9] M. Tollenaar, E.A. Lee, Strategies for Enhancing Grain Yield in Maize, in: J. Janick, (Eds.), Plant Breeding Reviews, Vol. 34, John Wiley \& Sons, 2011.

[10] B. Goffinet, S. Gerber, Quantitative trait loci: a meta-analysis, Genetics 155 (2000) 463-473.

[11] A. Arcade, A. Labourdette, M. Falque, B. Mangin, F. Chardon, A. Charcosset, J. Joets, BioMercator: integrating genetic maps and QTL towards discovery of candidate genes, Bioinformatics 20 (2004) 2324-2326.

[12] F. Chardon, B. Virlon, L. Moreau, M. Falque, J. Joets, L. Decousset, A. Murigneux, A. Charcosset, Genetic architecture of flowering time in maize as inferred from quantitative trait loci meta-analysis and synteny conservation with the rice genome, Genetics 168 (2004) 2169-2185.

[13] S. Salvi, S. Castelletti, R. Tuberosa. An updated consensus map for flowering time QTLs in maize, Maydica 54 (2009) 501-512

[14] L. Ku, X. Wei, S. Zhang, J. Zhang, S. Guo, Y. Chen, Cloning and characterization of a putative Tacl ortholog associated with leaf angle in maize (Zea mays L.), PLoS One 6 (2011) 6.

[15] R.G. Sala, F.H. Andrade, J.C. Cerono, Quantitative trait loci associated with grain moisture at harvest for line per se and testcross performace in maize: a meta-analysis, Euphytica 185 (2012) 429440.

[16] K. Xiang, L.M. Reid, Z.M. Zhang, X.Y. Zhu, G.T. Pan, Characterization of correlation between grain moisture and ear rot resistance in maize by QTL meta-analysis, Euphytica 183 (2012) 185-195. 
[17] Z. Hao, X. Li, X. Liu, C. Xie, M. Li, D. Zhang, S. Zhang, Meta-analysis of constitutive and adaptive QTL for drought tolerance in maize, Euphytica 174 (2010) 165-177.

[18] J.Z. Li, Z.W. Zhang, Y.L. Li, Q.L. Wang, Y.G. Zhou, QTL consistency and meta-analysis for grain yield components in three generations in maize, Theor. Appl. Genet. 122 (2011) 771-782.

[19] K. Semagn, Y. Beyene, M.L. Warburton, A. Tarekegne, S. Mugo, B. Meisel, P. Sehabiague, B.M. Prasanna, Meta-analyses of QTL for grain yield and anthesis silking interval in 18 maize populations evaluated under water-stressed and well-watered environments, BMC Genomics 14 (2013) 313-328.

[20] Y. Wang, Z. Huang, D. Deng, H. Ding, R. Zhang, S. Wang, Y. Bian, Z. Yin, X. Xu, Metaanalysis combined with syntenic metaQTL mining dissects candidate loci for maize yield, Mol. Breeding 31 (2013) 601-614.

[21] C.C. Schön, B.S. Dhillon, H.F. Utz, A.E. Melchinger, High congruency of QTL positions for heterosis of grain yield in three crosses of maize, Theor. Appl. Genet. 120 (2010) 321-332.

[22] A. Lariepe, B. Mangin, S. Jasson, V. Combes, F. Dumas, P. Jamin, C. Lariagon, D. Jolivot, D. Madur, J. Fiévet, A. Gallais, P. Dubreuil, A. Charcosset, L. Moreau, The genetic basis of heterosis: multiparental quantitative trait loci mapping reveals contrasted levels of apparent overdominance among traits of agronomical interest in maize (Zea mays L.), Genetics 190 (2012) 795-811.

[23] A. Thiemann, J. Fu, F. Seifert, R.T. Grant-Downton, T.A. Schrag, H. Pospisil, M. Frisch, A.E. Melchinger, S. Scholten, Genome-wide meta-analysis of maize heterosis reveals the potential role of additive gene expression at pericentromeric loci, BMC Plant Biol. 14 (2014) 88-101.

[24] P. Ajmone-Marsan, G. Monfredini, W.F. Ludwig, A.E. Melchinger, P. Franceschini, G. Pagnotto, M. Motto, In an elite cross of maize a major quantitative trait locus controls $1 / 4$ of the genetic-variation for grain-yield, Theor. Appl. Genet. 90 (1995) 415-424.

[25] G.D. Almeida, D. Makumbi, C. Magorokosho, S. Nair, A. Borém, J.M. Ribaut, M. Bänziger, B.M. Prasanna, J. Crossa, R. Babu, QTL mapping in three tropical maize populations reveals a set of constitutive and adaptive genomic regions for drought tolerance, Theor. Appl. Genet. 126 (2013) 583600.

[26] Y. Barriere, V. Mechin, D. Denoue, C. Bauland, J. Laborde, QTL for yield, earliness, and cell wall quality traits in topcross experiments of the F838 x F286 early maize RIL progeny, Crop. Sci. 20 (2010) 1761-1772.

[27] M. Bohn, B. Schulz, R. Kreps, D. Klein, A.E. Melchinger, QTL mapping for resistance against the European corn borer (Ostrinia nubilalis H.) in early maturing European dent germplasm, Theor. Appl. Genet 101 (2002) 907-917. 
[28] H. Cai, Q. Chu, R Gu, L. Yuan, J. Liu, X. Zhang, F. Chen, G. Mi, F. Zhang, Identification of QTLs for plant height, ear height and grain yield in maize (Zea mays L.) in response to nitrogen and phosphorus supply, Plant Breeding 131 (2012) 502-510.

[29] R.A. Cañas, I. Quillere, A. Gallais, B. Hirel, Can genetic variability for nitrogen metabolism in the developing ear of maize be exploited to improve yield?, New Phytologist 194 (2012) 440-452.

[30] M. Coque, A. Gallais, Genomic regions involved in response to grain yield selection at high and low nitrogen fertilization in maize, Theor. Appl. Genet. 112 (2006) 1205-1220.

[31] E. Frascaroli, M.A. Cane, P. Landi, G. Pea, L. Gianfranceschi, M. Villa, M. Morgante, M.E. Pe, Classical genetic and quantitative trait loci analyses of heterosis in a maize hybrid between two elite inbred lines, Genetics 176 (2007) 625-644.

[32] J. Guo, Z. Chen, Z. Liu, B. Wang, W. Song, W. Li, J. Chen, J. Dai, J. Lai, Identification of genetic factors affecting plant density response through QTL mapping of yield component traits in maize (Zea mays L.), Euphytica 182 (2011) 409-422.

[33] Y.F. Huang, D. Madur, V. Combes, C.L. Ky, D. Coubriche, P. Jamin, S. Jouanne, F. Dumas, E. Bouty, P. Bertin, A. Charcosset, L. Moreau, The genetic architecture of grain yield and related traits in Zea mays L. revealed by comparing intermated and conventional populations, Genetics 186 (2010) 395-404.

[34] C. Jansen, N. Lauter, N. de Leon, C. Hirsch, L. Ruff, T. Lübberstedt, Genetic and morphometric analysis of cob architecture and biomass related traits in the intermated B73xMo17 recombinant inbred lines of maize, BioEnergy Research 6 (2013) 903-916.

[35] X.H. Li, X.D. Liu, M.S. Li, S.F. Zhan, Identification of quantitative trait loci for anthesis-silking interval and yield components under drought stress in maize, Acta Botanica Sinica 45 (2003) 852857.

[36] Y.L. Li, S.Z. Niu, Y.B. Dong, D.Q. Cui, Y.Z. Wang, Y.Y. Liu, M.G. Wei, Identification of traitimproving quantitative trait loci for grain yield components from a dent corn inbred line in an advanced backcross $\mathrm{BC} 2 \mathrm{~F} 2$ population and comparison with its $\mathrm{F} 2: 3$ population in popcorn, Theor. Appl. Genet. 115 (2007) 129-140.

[37] Y.L. Li, X.H. Li, J.Z. Li, J.F. Fu, Y.Z. Wang, M.G. Wei, Dent corn genetic background influences QTL detection for grain yield and yield components in high-oil maize, Euphytica 169 (2009) 273-284.

[38] X.H. Liu, P. Zheng, Z.B. Tan, Z. Li, C. He, Quantitative trait locus (QTL) mapping for 100kernel weight of maize (Zea mays L.) under different nitrogen regimes, Afri. J. of Biotechnol. 9 (2010) 8283-8289. 
[39] X.H. Liu, S.L. He, Z.P. Zheng, Y.B. Huang, Z.B. Tan, Z. Li, C. He, X. Wu, Q.B. Pu, Identification of the QTLs for grain yield using RIL population under different nitrogen regimes in maize, Afri. J. of Agric. Res. 5 (2010) 2002-2007.

[40] X.H. Liu, Z.P. Zheng, Z.B. Tan, Z. Li, C. He, Genetic analysis of two new quantitative trait loci for ear weight in maize inbred line Huangzao4, Genet. Mol. Res. 9 (2010) 2140-2147.

[41] X.H. Liu, S.L. He, Z.P. Zheng, Y.B. Huang, Z.B. Tan, X. Wu, QTL identification for row number per ear and grain number per row in maize, Maydica 55 (2010) 127-133.

[42] X.H. Liu, S.L. He, Z.P. Zheng, Z.B. Tan, Z. Li, C. He, Genetic loci mapping associated with maize kernel number per ear based on a recombinant inbred line population grown under different nitrogen regimes, Genet. Mol. Res. 10 (2011) 3267-3274.

[43] Z.H. Liu, H.Q. Ji, Z.T. Cui, X. Wu, L.J. Duan, X.X. Feng, J.H. Tang, QTL detected for grainfilling rate in maize using a RIL population, Mol. Breed. 27 (2011) 25-36.

[44] Y. Liu, L. Wang, C. Sun, Z. Zhang, Y. Zheng, F. Qiu, Genetic analysis and major QTL detection for maize kernel size and weight in multi- environments, Theor. Appl. Genet. 127 (2014) 1019-1037. [45] H. Lu, J. Romero Severson, R. Bernardo, Genetic basis of heterosis explored by simple sequence repeat markers in a random mated maize population, Theor. Appl. Genet. 107 (2003) 494-502.

[46] G.H. Lu, J.H. Tang, J.B. Yan, X.Q. Ma, J.S. Li, S.J. Chen, J.C. Ma, Z.X. Liu, L.Z. E, Y.R. Zhang, J.R. Dai, Quantitative trait loci mapping of maize yield and its components under different water treatments at flowering time, J. Integr. Plant Biol. 48 (2006) 1233-1243.

[47] M. Lu, C.X. Xie, X.H. Li, Z.F. Hao, M.S. Li, J.F. Weng, D.G. Zhang, B. Li, S.H. Zhang, Mapping of quantitative trait loci for kernel row number in maize across seven environments, Mol. Breed. 28 (2011) 143-152.

[48] R. Marino, M. Ponnaiah, P. Krajewski, C. Frova, L. Gianfranceschi, M.E. Pè, M. Sari-Gorla, Addressing drought tolerance in maize by transcriptional profiling and mapping, Mol. Genet. Genomics 281 (2009) 163-179.

[49] A.E. Melchinger, H.F. Utz, C.C. Charlesworth, Quantitative trait locus (QTL) mapping using different testers and independent population samples in maize reveals low power of QTL detection and large bias in estimates of QTL effects, Genetics 149 (1998) 383-403.

[50] R. Messmer, Y. Fracheboud, M. Bänziger, M. Vargas, P. Stamp, J.M. Ribaut, Drought stress and tropical maize: QTL-by-environment interactions and stability of QTLs across environments for yield components and secondary traits, Theor. Appl. Genet. 119 (2009) 913-930.

[51] L. Moreau, A. Charcosset, A. Gallais, Use of trial clustering to study QTL x environment effects for grain yield and related traits in maize, Theor. Appl. Genet. 110 (2004) 92-105. 
[52] J.M. Ribaut, C. Jiang, D. Gonzalez de Leon, G.O. Edmeades, D.A. Hoisington, Identification of quantitative trait loci under drought conditions in tropical maize 2. Yield components and markerassisted selection strategies, Theor. Appl. Genet. 94 (1997) 887-896.

[53] J.M. Ribaut, Y. Fracheboud, P. Monneveux, M. Banziger, M. Vargas, C. Jiang, Quantitative trait loci for yield and correlated traits under high and low soil nitrogen conditions in tropical maize, Mol. Breed. 20 (2007) 15-29.

[54] C.W. Stuber, S.E. Lincoln, D.W. Wolff, T. Helentjarisn, E.S. Lander, Identification of genetic factors contributing to heterosis in a hybrid from two elite maize inbred lines using molecular markers, Genetics 132 (1992) 823-839.

[55] J. Tang, J. Yan, X. Ma, W. Teng, W. Wu, J. Dai, B.S. Dhillon, A.E. Melchinger, J. Li, Dissection of the genetic basis of heterosis in an elite maize hybrid by QTL mapping in an immortalized F-2 population, Theor. Appl. Genet. 120 (2010) 333-340.

[56] B. Tian, J. Wang, G. Wang, Confirmation of a major QTL on chromosome 10 for maize kernel row number in different environments, Plant Breeding 133 (2014) 184-188.

[57] R. Tuberosa, M.C. Sanguineti, P. Landi, M.M. Giuliani, S. Salvi, S. Conti, Identification of QTLs for root characteristics in maize grown in hydroponics and analysis of their overlap with QTs for grain yield in the field at two water regimes, Plant Mol. Biol. 48 (2002) 697-712.

[58] L.R. Veldboom, M. Lee, Molecular-marker-facilitated studies of morphological traits in maize.

2. Determination of QTLs for grain-yield and yield components. Theor. Appl. Genet. 89 (1994) 451458.

[59] J.J. Wassom, J.C. Wong, E. Martinez, J.J. King, J. De Baene, J.R. Hotchkiss, V. Mikkilineni, M.O. Bohn, T.R. Rocheford, QTL associated with maize kernel oil, protein, and starch concentrations, kernel mass, and grain yield in Illinois High Oil x B73 backcross-derived lines, Crop Sci. 48 (2008) 243-252.

[60] Y.N. Xiao, X.H. Li, M.L. George, M.S. Li, S.H. Zhang, Y.L. Zheng, Quantitative trait locus analysis of drought tolerance and yield in maize in China, Plant Mol. Biol. Rep. 23 (2005) 155-165. [61] J. Yan, H. Tang, Y. Huang, Y. Zheng, C. Subhash, J. Li, A genome scan for quantitative trait loci affecting grain yield and its components of maize both in single-and two-locus levels, Chinese Sci. Bull. 51 (2006) 1452-1461.

[62] G. Yang, Y. Li, Q. Wang, Y. Zhou, Q. Zhou, B. Shen, F. Zhang, X. Liang, Detection and integration of quantitative trait loci for grain yield components and oil content in two connected recombinant inbred line populations of high-oil maize, Mol. Breeding 29 (2012) 313-333. 
[63] H. Zhang, Z. Zheng, X. Liu, Z. Li, C. He, D. Liu, Y. Luo, G. Zhang, Z. Tan, R. Li, QTL mapping for ear length and ear diameter under different nitrogen regimes in maize, Afr. J. Agric. Res. 5 (2010) 626-630.

[64] Z. Zhang, Z. Liu, Y. Hu, W. Li, Z. Fu, D. Ding, H. Li, M. Qiao, J. Tang, QTL analysis of kernelrelated traits in maize using an immortalized F2 population, PLOS One 9 (2014) e89645

[65] H.J. Zheng, A.Z. Wu, C.C. Zheng, Y.F. Wang, R. Cai, X.F. Shen, R.R. Xu, P. Liu, L.J. Kong, S.T. Dong, QTL mapping of maize (Zea mays) stay-green traits and their relationship to yield, Plant Breeding 128 (2009) 54-62.

[66] A. Darvasi, M. Soller, A simple method to calculate resolving power and confidence interval of QTL map location, Behav. Genet. 27 (1997) 125-132.

[67] B. Guo, D.A. Sleper, J. Sun, H.T. Nguyen, P.R. Arelli, J.G. Shannon, Pooled analysis of data from multiple quantitative trait locus mapping populations, Theor. Appl. Genet. 113 (2006) 39-48.

[68] C.J. Lawrence, T.E. Seigfried, V. Brendel, The maize genetics and genomics database: the community resource for access to diverse maize data, Plant Physiol. 138 (2005) 55-58.

[69] O. Sosnowski, A. Charcosset, J. Joets, BioMercator V3: an upgrade of genetic map compilation and quantitative trait loci meta-analysis algorithms, Bioinformatics 28 (2012) 2082-2083.

[70] C.M. Andorf, C.J. Lawrence, L.C. Harper, M.L. Schaeffer, D.A. Campbell, T.Z. Sen, The Locus Lookup tool at MaizeGDB: identification of genomic regions in maize by integrating sequence information with physical and genetic maps. Bioinformatics 26 (2010) 434-436.

[71] T.K. Wolfgruber, A. Sharma, K.L. Schneider, P.S. Albert, D.H. Koo, J. Shi, Z. Gao, F. Han, H. Lee, R. Xu, J. Allison, J.A. Birchler, J. Jiang, R.K. Dawe, G.G. Presting, Maize centromere structure and evolution: sequence analysis of centromeres 2 and 5 reveals dynamic loci shaped primarily by retrotransposons, PLoS Genet, (2009) e1000743.

[72] M.W. Ganal, G. Durstewitz, A. Polley, A. Bérard, E.S. Buckler, A. Charcosset, J.D. Clarke, E.M. Graner, M. Hansen, J. Joets, M.C. Le Paslier, M.D. McMullen, P. Montalent, M. Rose, C.C. Schön, Q. Sun, H. Walter, O.C. Martin, M. Falque, A large maize (Zea mays L.) SNP genotyping array: development and germplasm genotyping, and genetic mapping to compare with the B73 reference genome PLoS ONE 6 (2011) e28334.

[73] M. Krzywinski, J. Schein, İ. Birol, J. Connors, R. Gascoyne, D. Horsman, M.A. Marra, Circos: An information aesthetic for comparative genomics, Genome Res. 19 (2009) 639-1645.

[74] J. Flint, T.F. Mackay, Genetic architecture of quantitative traits in mice, flies, and humans, Genome Res. 19 (2009) 723-733.

[75] P.S. Schnable et al., The B73 maize genome: complexity, diversity, and dynamics, Science 326 (2009) 1112-1115. 
[76] E. Rodgers-Melnick, P.J. Bradbury, R. J. Elshire, J.C. Glaubitz, C.B. Acharya, S. E. Mitchell, C. Li, Y. Li, E.S. Buckler, Recombination in diverse maize is stable, predictable, and associated with genetic load, PNAS 112 (2015) 3823-3828.

[77] J.M. Chia, C. Song, P.J. Bradbury, D. Costich, N. De Leon, J. Doebley et al. Maize HapMap2 identifies extant variation from a genome in flux, Nat. Genet. 44 (2012) 803-807.

[78] S. Mezmouk, J. Ross-Ibarra, The pattern and distribution of deleterious mutations in maize, G3 4 (2014) 163-171.

[79] M.C. Romay, M.J. Millard, J.C. Glaubitz, J.A. Peiffer, K.L. Swarts, T.M. Casstevens, R.J. Elshire, C.B. Acharya, S.E. Mitchell, S.A. Flint-Garcia, M.D. McMullen, J.B. Holland, E.S. Buckler, C.A. Gardner. Comprehensive genotyping of the USA national maize inbred seed bank, Genome Biol 14 (2013) R55

[80] X. Li, C. Zhu, C.T. Yeh, W. Wu, E.M. Takacs, K.A. Petsch, F. Tian, G. Bai, E.S. Buckler, G.J. Muehlbauer, M.C. Timmermans, M.J. Scanlon, P.S. Schnable, J. Yu, Genic and nongenic contributions to natural variation of quantitative traits in maize, Genome Res. 22 (2012) 2436-44.

[81] M. Hartfield, S.P. Otto, Recombination and hitchhiking of deleterious alleles, Evolution 65 (2011) 2421-2434.

[82] D. Charlesworth, J.H. Willis, The genetics of inbreeding depression, Nat. Rev. Genet. 10 (2009) 783-796.

[83] M.D. McMullen, S. Kresovich, H. Villeda, P. Bradbury, H. Li, Q. Sun, S. Flint-Garcia, J. Thornsberry, C. Acharya, C. Bottoms, P. Brown, C. Browne, M. Eller, K. Guill, C. Harjes, D. Kroon, N. Lepak, S.E. Mitchell, B. Peterson, G. Pressoir, S. Romero, M. Oropeza Rosas, S. Salvo, H. Yates, M. Hanson, E. Jones, S. Smith, J.C. Glaubitz, M. Goodman, D. Ware, J.B. Holland, E.S. Buckler, Genetic properties of the maize nested association mapping population, Science 325 (2009) 737-740. [84] S. Salvi, G. Sponza, M. Morgante, D. Tomes, X. Niu, K.A. Fengler, R. Meeley, E.V. Ananiev, S. Svitashev, E. Bruggemann, B. Li, C.F. Hainey, S. Radovic, G. Zaina, J.A. Rafalski, G.H. Miao, R.L. Phillips, R. Tuberosa, Conserved noncoding genomic sequences associated with a floweringtime quantitative trait locus in maize, Proc. Natl. Acad. Sci. USA 104 (2007) 11376-11381.

[85] S. Bouchet, B. Servin, P. Bertin, D. Madur, V. Combes, F. Dumas, D. Brunel, J. Laborde, A. Charcosset, S. Nicolas, Adaptation of maize to temperate climates: mid-density genome-wide association genetics and diversity patterns reveal key genomic regions, with a major contribution of the Vgt2 (ZCN8) locus, PLoS One 8 (2013) e71377.

[86] R.M. Clark, E. Linton J. Messing, J.F. Doebley, Pattern of diversity in the genomic region near the maize domestication gene tb1, Proc. Nat. Acad. Sci USA 101 (2004) 700-707. 
[87] F. Tian, N.M. Stevens, E.S. Buckler IV, Tracking footprints of maize domestication and evidence for a massive selective sweep on chromosome 10, Proc. Nat. Acad. Sci USA 106 (2009) 9979-9986. [88] P. Bommert, N.S. Nagasawa, D. Jackson, Quantitative variation in maize kernel row number is controlled by the FASCIATED EAR2 locus, Nature Genetics 45 (2013) 334-338.

[89] M. Löffler, C.C. Schoen, T. Miedaner, Revealing the genetic architecture of FHB resistance in hexaploid wheat (Triticum aestivum L.) by QTL meta-analysis, Mol. Breed. 23 (2009) 473-488.

[90] S.Salvi, R. Tuberosa, Cloning QTLs in plants, in: RK. Varshney, R. Tuberosa, (Eds.) GenomicsAssisted Crop Improvement, Vol. 1: Genomics Approaches and Platforms, Springer (Dordrecht Netherlands) 2007, pp. 207 - 226.

[91] F. Tardieu, R.Tuberosa, Dissection and modelling of abiotic stress tolerance in plants, Curr. Opin. Plant Biol. 13 (2010) 206-212 


\section{Table 1}

List of trait categories utilized in this study.

\begin{tabular}{|c|c|c|}
\hline Trait & Acronym & Traits included ${ }^{1}$ \\
\hline Grain Yield $^{2}$ & GY & Grain yield \\
\hline \multirow[t]{4}{*}{ Kernel Weight } & KW & Hundred Kernel Weight \\
\hline & & Kernel Weight \\
\hline & & Kernel Weight per Ear \\
\hline & & Thousand Kernel Weight \\
\hline Ear Row Number & ERN & Ear row number \\
\hline \multirow[t]{4}{*}{ Kernel Number } & $\mathrm{KN}$ & Kernel Number \\
\hline & & Kernel Number per Ear \\
\hline & & Kernel Number per Plant \\
\hline & & Kernel Number per Row \\
\hline Ear Length & EL & Ear Length \\
\hline Ear Diameter & ED & Ear Diameter \\
\hline \multirow[t]{2}{*}{ Ear Number } & EN & Ear Number \\
\hline & & Ear Number per Plant \\
\hline Ear Weight & EW & Ear Weight \\
\hline \multicolumn{3}{|c|}{$\begin{array}{l}\text { Traits as defined from original papers which were } \\
\text { included in the same category in our study. }\end{array}$} \\
\hline \multicolumn{3}{|c|}{$\begin{array}{l}{ }^{2} \text { Grain Yield trait category strictly included QTL data for } \\
\text { overall grain production per unit of area, with the } \\
\text { exception of QTL information from studies [18] and [37], } \\
\text { where Ear weight per plant and Grain weight per plant } \\
\text { were provided and utilized, respectively. }\end{array}$} \\
\hline
\end{tabular}




\section{Table 2}

Summary of QTL studies included in QTL meta-analysis for grain yield and grain yield related traits.

\begin{tabular}{|c|c|c|c|c|c|c|c|}
\hline Reference & Cross & Population type $^{\text {a }}$ & Size & $\begin{array}{l}\text { Exp. } \\
\text { (no.) }{ }^{\mathrm{b}}\end{array}$ & Traits $^{\mathrm{c}}$ & Notes & QTLs (no.) \\
\hline Ajmone Marsan et al. [24] & B73 x A7 & $\mathrm{F} 3$ as $\mathrm{TC}$ & 232 & 1 & GY, TW & Testers: A1, Mo17 & 11 \\
\hline Almeida et al. [25] & $\begin{array}{l}\text { CML444xSC-Malawi (234) } \\
\text { CML444xCML441 (300) } \\
\text { CML440xCML504 (247) }\end{array}$ & $\begin{array}{l}\text { RIL as TC } \\
\text { F2:3 as TC } \\
\text { F2:3 as TC }\end{array}$ & 781 & 2 & GY & $\begin{array}{l}\text { WW and WS; Testers:CM312, } \\
\text { CML395 }\end{array}$ & 17 \\
\hline Barriere et al. [26] & F838 x F826 & RIL as TC & 240 & 1 & GY & Tester: F353 & 8 \\
\hline Bohn et al. [27] & D06 x D408 & F3 & 230 & 1 & GY & & 6 \\
\hline Cai et al. [28] & Ye478 x Wu312 & RIL & 218 & 3 & EL, GY, KN, KW & LN, LP, normal $\mathrm{N}$ and $\mathrm{P}$ & 47 \\
\hline Cañas et al. [29] & Io $\mathrm{x} F 2$ & RIL & 100 & 1 & EN, EL & & 2 \\
\hline Coque \& Gallais [30] & Io $\mathrm{x} F 2$ & RIL as TC & 99 & 2 & $\mathrm{GY}, \mathrm{KW}, \mathrm{KN}$ & HN and LN; Tester: F252 & 23 \\
\hline Frascaroli et al. [31] & B73 x H99 & RIL as BC/TC & 142 & 1 & $\mathrm{GY}, \mathrm{KN}, \mathrm{KW}$ & Testers: B73, H99, their F1 & 46 \\
\hline Guo et al. [32] & Zheng58 x Chang7-2 & $\mathrm{F} 2: 3$ & 231 & 2 & EW, KW, EL, ERN, KN, ED & Low density, High density & 37 \\
\hline Huang et al. [33] & $\mathrm{F} 2 \times \mathrm{F} 252$ & $\begin{array}{l}\text { F3:4 and IF3 as } \\
\text { TC }\end{array}$ & $\begin{array}{l}300, \\
322\end{array}$ & 1 & GY & Tester: MBS847 & 16 \\
\hline Jansen et al. [34] & B73 x Mo17 & RIL (IBMSyn4) & 206 & 1 & GY, KW & & 9 \\
\hline Lariepe et al. [22] & $\begin{array}{l}\text { IoxF252 (144); F2xF252 } \\
\text { (113); F2xIo (145) }\end{array}$ & RIL as BC/TC & 402 & 1 & GY & Testers: F2, F252, Io & 10 \\
\hline Li et al. [35] & Huangzao 4 x Ye 107 & F3 & 184 & 2 & GY & WW and WS & 9 \\
\hline Li et al. [36] & Dan232 x N04 & $\mathrm{F} 2: 3$ & 259 & 1 & $\mathrm{KW}, \mathrm{EL}, \mathrm{ED}, \mathrm{ERN}, \mathrm{KN}$ & & 16 \\
\hline \multirow[t]{2}{*}{ Li et al. [37] } & 8984 x GY220 & $\mathrm{F} 2: 3$ & 284 & 1 & GY, KW, EL, ED, ERN, KN & & 18 \\
\hline & 8622 x GY220 & $\mathrm{F} 2: 3$ & 265 & 1 & GY, KW, EL, ED, ERN, KN & & 14 \\
\hline Li et al. [18] & Dan232 x N04 & RIL & 258 & 5 & $\begin{array}{l}\text { GY, EW, KW, EL, ERN, KN, } \\
\text { ED }\end{array}$ & & 58 \\
\hline Liu et al. [38] & Huangzao4 x Mo17 & RIL & 239 & 2 & KW & $\mathrm{HN}$ and $\mathrm{LN}$ & 4 \\
\hline Liu et al. [39] & Huangzao4 x Mo17 & RIL & 239 & 2 & GY & $\mathrm{HN}$ and $\mathrm{LN}$ & 6 \\
\hline Liu et al. [40] & Huangzao4 x Mo17 & RIL & 239 & 2 & EW & $\mathrm{HN}$ and $\mathrm{LN}$ & 2 \\
\hline Liu et al. [41] & Huangzao4 x Mo17 & RIL & 239 & 2 & ERN, KN & $\mathrm{HN}$ and $\mathrm{LN}$ & 8 \\
\hline Liu et al. [42] & Huangzao4 x Mo17 & RIL & 239 & 2 & $\mathrm{KN}$ & $\mathrm{HN}$ and $\mathrm{LN}$ & 7 \\
\hline \multirow[t]{2}{*}{ Liu et al. [43] } & Ye478 x Wu312 & RIL & 218 & 2 & GY & & 5 \\
\hline & & $\mathrm{BC} 4 \mathrm{~F} 3$ & 187 & 2 & GY & & 5 \\
\hline
\end{tabular}




\begin{tabular}{|c|c|c|c|c|c|c|c|}
\hline Liu et al. [44] & Mc x V671 & $\mathrm{F} 2: 3$ & 270 & 1 & KW & & 9 \\
\hline Lu et al. [45] & LH200 x LH216 & F2syn as BC & 351 & 1 & GY & Testers: LH200, LH216 & 29 \\
\hline Lu et al. [46] & Zong 3 x 87-1 & RIL & 221 & 2 & GY, EL, KN, KW & WW and WS & 26 \\
\hline Lu et al. [47] & Ye478 x Dan340 & $\mathrm{F} 2: 3$ & 397 & 1 & ERN & & 13 \\
\hline Marino et al. [48] & B73 x H99 & RIL & 142 & 1 & EL, EW, KW, KN & & 22 \\
\hline Melchinger et al. [49] & KW1265 x D146 & $\mathrm{F} 3$ as $\mathrm{TC}$ & 451 & 1 & GY, KW & Testers: KW4115, KW5361 & 20 \\
\hline Messmer et al. [50] & CML444 x SC-Malawi & RIL & 236 & 2 & $\mathrm{GY}, \mathrm{KW}, \mathrm{KN}$ & WW and WS & 20 \\
\hline Moreau et al. [51] & $\mathrm{F} 2 \times \mathrm{F} 252$ & $\mathrm{~F} 3: 4$ as $\mathrm{TC}$ & 300 & 1 & $\mathrm{GY}, \mathrm{KW}, \mathrm{KN}$ & Tester: MBS847 & 13 \\
\hline Ribaut et al. [52] & $\begin{array}{l}\text { Ac7643S5 x } \\
\text { Ac7729/TZSRWS5 }\end{array}$ & F3 & 234 & 4 & GY, EN, KN & WW, IS, WS and IS+WS & 30 \\
\hline Ribaut et al. [53] & $\begin{array}{l}\text { Ac7643S5 x } \\
\text { Ac7729/TZSRWS5 }\end{array}$ & $\mathrm{F} 3$ & 240 & 2 & $\mathrm{GY}, \mathrm{KN}, \mathrm{KW}, \mathrm{EN}$ & $\mathrm{HN}$ and $\mathrm{LN}$ & 21 \\
\hline Stuber et al. [54] & B73 x Mo17 & $\mathrm{F} 3$ as $\mathrm{BC}$ & 264 & 1 & GY & Recurrent parents: B73, Mo17 & 11 \\
\hline Tang et al. [55] & Zong3 x 87-1 & IF2 & 294 & 1 & GY, EL, ERN, KW & & 8 \\
\hline Tian et al. [56] & Y1648 x Y2348 & $\mathrm{F} 2: 3, \mathrm{~F} 2: 4$ & 180 & 1 & ERN & & 9 \\
\hline Tuberosa et al. [57] & Lo964 x Lo1016 & $\mathrm{F} 3$ & 171 & 2 & GY & WW and WS & 13 \\
\hline Veldboom et al. [58] & Mo17 x H99 & $\mathrm{F} 2: 3$ & 150 & 1 & GY, KW, EN, EL, ED, ERN & & 21 \\
\hline Wassom et al. [59] & $(((\mathrm{IHO} 90 \times \mathrm{B} 73) \times \mathrm{B} 73) \mathrm{S} 1)$ & $\mathrm{BC} 1 \mathrm{~S} 1$ as $\mathrm{TC}$ & 150 & 1 & GY & Tester: Mo17 & 3 \\
\hline Xiao et al. [60] & $\mathrm{B} 73 \times \mathrm{X} 178$ & $\mathrm{~F} 2: 3$ & 234 & 2 & KW, EN, EW, GY, KN & WW and WS & 26 \\
\hline Yan et al. [61] & Zong3 x 87-1 & $\mathrm{F} 2: 3$ & 266 & 1 & GY, KN, ERN, KW & & 20 \\
\hline \multirow[t]{2}{*}{ Yang et al. [62] } & 8984 x GY220 & RIL & 282 & 1 & $\begin{array}{l}\text { GY, EW, KN, KW, EL, ED, } \\
\text { ERN }\end{array}$ & & 48 \\
\hline & 8622 x GY220 & RIL & 263 & 1 & $\begin{array}{l}\text { GY, EW, KN, KW, EL, ED, } \\
\text { ERN }\end{array}$ & & 40 \\
\hline Zhang et al. [63] & Huangzao4 x Mo17 & RIL & 239 & 2 & EL, ED & $\mathrm{HN}$ and $\mathrm{LN}$ & 5 \\
\hline Zhang et al. [64] & Huang C x Xu178 & IF2 & 243 & 1 & KW & & 6 \\
\hline Zheng et al. [65] & Qi-319 x Mo17 & $\mathrm{F} 2: 3$ & 166 & 1 & GY, ED, KW & & 11 \\
\hline
\end{tabular}

a RIL: recombinant inbred line; TC: testcross, BC: backcross; IF2: immortalized F2;

${ }^{\mathbf{b}}$ Number of experiments

${ }^{\mathrm{c}} \mathrm{GY}$ : grain yield, KW: kernel weight, KN: kernel number, ER: ear number, ERN: ear row number, EW: ear weight, EL: ear length, ED: ear diameter.

WS: water stress, WW: well watered, IS: intermediate stress, HN: high nitrogen, LN: low nitrogen, LP: low phosphorus. 
Table 3

Summary of MQTL information for grain yield and grain yield-related traits.

\begin{tabular}{|c|c|c|c|c|c|}
\hline Chromosome & MQTL & Position $^{a}$ & $\begin{array}{c}\mathrm{CI}^{\mathrm{b}} \\
(\mathrm{cM})\end{array}$ & $\begin{array}{l}\text { QTLs }^{c} \\
\text { (no.) }\end{array}$ & Traits \\
\hline \multirow[t]{9}{*}{1} & 1 & 40.69 & 2.48 & 33 & ED, EL, EN, ERN, GY, KN, KW \\
\hline & 2 & 75.2 & 2.09 & 7 & $\mathrm{EL}, \mathrm{KN}, \mathrm{KW}$ \\
\hline & 3 & 100.31 & 1.08 & 12 & ED, EW, GY, KN, KW \\
\hline & 4 & 112.72 & 2.74 & 7 & EL, GY, KW \\
\hline & 5 & 132.52 & 3.24 & 6 & $\mathrm{ED}, \mathrm{GY}, \mathrm{KN}, \mathrm{KW}$ \\
\hline & 6 & 139.7 & 0.1 & 3 & GY, KW \\
\hline & 7 & 162.37 & 2.48 & 19 & ED, EL, ERN, GY, KN, KW \\
\hline & 8 & 191.91 & 3.11 & 6 & ED, GY \\
\hline & 9 & 243.49 & 0.65 & 16 & EL, EN, ERN, EW, GY, KN, KW \\
\hline \multirow[t]{10}{*}{2} & 10 & 10.57 & 3.06 & 6 & ED, EL, EW, KN, KW \\
\hline & 11 & 33.13 & 6.29 & 3 & ERN, GY, KW \\
\hline & 12 & 49.27 & 8.31 & 1 & KW \\
\hline & 13 & 61.1 & 0.2 & 4 & GY, KW \\
\hline & 14 & 71.72 & 3.96 & 7 & EN, GY, KW \\
\hline & 15 & 85.48 & 4.75 & 5 & $\mathrm{GY}, \mathrm{KN}, \mathrm{KW}$ \\
\hline & 16 & 96.58 & 3.99 & 7 & ERN, GY, KW \\
\hline & 17 & 112.5 & 1.91 & 6 & ED, EL, ERN, GY, KN \\
\hline & 18 & 124.66 & 3.74 & 2 & GY, KW \\
\hline & 19 & 152.75 & 0.78 & 9 & ED, EL, EW, GY, KW \\
\hline \multirow[t]{8}{*}{3} & 20 & 8.06 & 3.72 & 11 & ED, EL, ERN, GY, KN, KW \\
\hline & 21 & 34.43 & 3.27 & 11 & ERN, EW, GY, KN, KW \\
\hline & 22 & 47.13 & 3.58 & 11 & ED, EL, EW, GY, KN, KW \\
\hline & 23 & 68.08 & 4.42 & 8 & EL, ERN, EW, KN, KW \\
\hline & 24 & 90.73 & 4.75 & 6 & EW, GY, KN \\
\hline & 25 & 105.94 & 5.28 & 5 & EN, ERN, GY, KN \\
\hline & 26 & 139.01 & 2.97 & 6 & ERN, GY, KN, KW \\
\hline & 27 & 172.73 & 0.7 & 7 & ED, EL, ERN, KW \\
\hline \multirow[t]{10}{*}{4} & 28 & 13.38 & 2.07 & 12 & ED, EL, ERN, EW, GY, KN, KW \\
\hline & 29 & 46.55 & 3.14 & 5 & ERN, EW, GY \\
\hline & 30 & 65.37 & 3.9 & 4 & EL, GY, KN \\
\hline & 31 & 76.04 & 4.35 & 8 & ED, ERN, GY, KN \\
\hline & 32 & 96.08 & 3.08 & 4 & EL, ERN, KW \\
\hline & 33 & 104.55 & 1.08 & 5 & ED, ERN, KW \\
\hline & 34 & 127.13 & 2.55 & 6 & ED, ERN, GY, KN, KW \\
\hline & 35 & 135.72 & 3.75 & 4 & ERN, GY \\
\hline & 36 & 146.46 & 3.7 & 8 & ED, ERN, GY, KN \\
\hline & 37 & 170.18 & 0.28 & 9 & ED, EL, ERN, GY, KN, KW \\
\hline \multirow[t]{8}{*}{5} & 38 & 3.91 & 3.13 & 3 & EL, GY, KN \\
\hline & 39 & 31.44 & 3.64 & 9 & EL, ERN, KN, KW \\
\hline & 40 & 47.22 & 2.28 & 10 & EL, ERN, EW, KW \\
\hline & 41 & 63.54 & 2.73 & 14 & EL, EW, GY, KN, KW \\
\hline & 42 & 84.21 & 1.96 & 16 & ED, ERN, GY, KN, KW \\
\hline & 43 & 108.62 & 4.97 & 5 & EL, ERN, GY, KW \\
\hline & 44 & 117.36 & 3.62 & 2 & $\mathrm{ED}, \mathrm{KW}$ \\
\hline & 45 & 135.36 & 0.33 & 12 & EL, GY, KN, KW \\
\hline \multirow[t]{4}{*}{6} & 46 & 25.54 & 2.18 & 23 & EL, EW, GY, KN, KW \\
\hline & 47 & 48 & 3.17 & 8 & GY, KN, KW \\
\hline & 48 & 62.75 & 8.78 & 2 & ERN, KW \\
\hline & 49 & 94.59 & 2.22 & 8 & ED, EL, EN, GY, KN, KW \\
\hline
\end{tabular}




\begin{tabular}{|c|c|c|c|c|c|}
\hline & 50 & 114.5 & 2.1 & 6 & ED, ERN, GY, KW \\
\hline & 51 & 131.34 & 1.24 & 5 & $\mathrm{EL}, \mathrm{GY}, \mathrm{KN}, \mathrm{KW}$ \\
\hline \multirow[t]{6}{*}{7} & 52 & 31.85 & 2.39 & 16 & ED, ERN, GY, KN, KW \\
\hline & 53 & 64.69 & 1.71 & 10 & ED, EL, GY, KN, KW \\
\hline & 54 & 76.52 & 3.47 & 8 & $\mathrm{EW}, \mathrm{GY}, \mathrm{KW}$ \\
\hline & 55 & 88.08 & 1.81 & 7 & ERN, GY, KW \\
\hline & 56 & 113.52 & 1.57 & 9 & EL, ERN, GY, KN, KW \\
\hline & 57 & 144.95 & 1.49 & 4 & $\mathrm{EL}, \mathrm{GY}, \mathrm{KN}$ \\
\hline \multirow[t]{9}{*}{8} & 58 & 25.03 & 4.57 & 4 & $\mathrm{GY}, \mathrm{KN}, \mathrm{KW}$ \\
\hline & 59 & 49.18 & 2.28 & 8 & ERN, GY, KN, KW \\
\hline & 60 & 57.09 & 2.8 & 6 & ERN, GY, KN, KW \\
\hline & 61 & 67.4 & 6.16 & 4 & $\mathrm{GY}, \mathrm{KN}$ \\
\hline & 62 & 87.89 & 4.45 & 6 & ERN, GY, KW \\
\hline & 63 & 92.81 & 1.27 & 7 & $\mathrm{EL}, \mathrm{EW}, \mathrm{GY}, \mathrm{KW}$ \\
\hline & 64 & 105.3 & 3.6 & 8 & ED, EL, EN, ERN, GY, KN \\
\hline & 65 & 121.99 & 2.63 & 8 & $\mathrm{EL}, \mathrm{EN}, \mathrm{GY}, \mathrm{KN}, \mathrm{KW}$ \\
\hline & 66 & 142.49 & 2.03 & 2 & $\mathrm{EL}, \mathrm{KN}$ \\
\hline \multirow[t]{10}{*}{9} & 67 & 6.05 & 1.8 & 2 & $\mathrm{KW}$ \\
\hline & 68 & 27.95 & 3.95 & 6 & $\mathrm{EW}, \mathrm{GY}, \mathrm{KN}, \mathrm{KW}$ \\
\hline & 69 & 50.82 & 3.18 & 7 & ED, EN, ERN, GY, KN, KW \\
\hline & 70 & 62.14 & 3.31 & 6 & $\mathrm{ED}, \mathrm{EN}, \mathrm{GY}, \mathrm{KN}, \mathrm{KW}$ \\
\hline & 71 & 66.26 & 2.21 & 5 & ERN, EW, GY \\
\hline & 72 & 76.29 & 5.32 & 4 & $\mathrm{EL}, \mathrm{ERN}, \mathrm{GY}, \mathrm{KN}$ \\
\hline & 73 & 85.61 & 6.33 & 2 & $\mathrm{EW}, \mathrm{KN}$ \\
\hline & 74 & 96.54 & 5.16 & 3 & GY, KW \\
\hline & 75 & 107.66 & 4.06 & 5 & EN, ERN, GY, KN, KW \\
\hline & 76 & 147.25 & 1.94 & 4 & EL, ERN, GY, KW \\
\hline \multirow[t]{8}{*}{10} & 77 & 27.39 & 7.37 & 6 & $\mathrm{EL}, \mathrm{GY}, \mathrm{KN}$ \\
\hline & 78 & 56.63 & 3.26 & 7 & EL, ERN, EW, GY \\
\hline & 79 & 67.08 & 3.64 & 8 & $\mathrm{EL}, \mathrm{GY}, \mathrm{KN}, \mathrm{KW}$ \\
\hline & 80 & 80.63 & 4.27 & 4 & $\mathrm{EL}, \mathrm{GY}, \mathrm{KN}, \mathrm{KW}$ \\
\hline & 81 & 89.02 & 2.68 & 10 & ED, EL, ERN, EW, GY, KW \\
\hline & 82 & 101.17 & 1.28 & 7 & ERN, EW, GY, KN, KW \\
\hline & 83 & 119.72 & 3.79 & 4 & ERN, GY, KW \\
\hline & 84 & 132.09 & 1.09 & 1 & KW \\
\hline
\end{tabular}

${ }^{\text {a }}$ Most probable position on the consensus map in $\mathrm{cM}$.

${ }^{\mathrm{b}}$ Length of the $95 \%$ confidence interval (CI) centered on the most probable position in $\mathrm{cM}$

${ }^{\mathrm{c}}$ Number of QTLs corresponding to the same MQTL 


\section{Figure legends}

Figure 1. Concentric circles showing yield QTL distribution on: A) maize reference map 'Genetic' and B) B73 RefGen_v2 reference genome. 1) Reference chromosomes with positions of bins as alternating gray and white bands. Approximate centromere positions are indicated by black bands. 2) QTL positions represented by confidence interval. Red bars correspond to QTLs with heterotic effect (HQ) and black bars correspond to all other QTLs. 3) Frequency of QTLs computed as QTL-overview index (Chardon et al., 2004). 4) MQTLs position with a CI of $95 \%$.

Figure 2. Distribution of QTLs on chromosomes expressed as QTL frequency (\%) per bin distance (20 cM- or $25 \mathrm{Mb}$-bin) from centromere. Histograms report mean QTL frequency values of ten chromosomes, with the following exceptions: $-60 \mathrm{cM}$, mean value of six chrs; $-40 \mathrm{cM}$, nine chrs; $+100 \mathrm{cM}$, eight chrs; $-75 \mathrm{Mb}$, five chrs; $+125 \mathrm{Mb}, 6 \mathrm{chrs}$. A and B) Distribution of all QTLs (total no.: 808). C and D) Distribution of 342 QTL with heterotic and potentially heterotic effects (PHQ). E and F) Distribution of 91 additive grain yield QTLs (GY AQ) and 96 heterotic grain yield QTLs (GY HQ). See Materials and Methods for definition of AQ, HQ and PHQ QTLs.

\section{Supplementary Materials}

Supp Mat 1. Grain yield and grain yield components QTLome database.

Supp Mat 2. Database of QTLs projected onto the maize 'Genetic' map and ready to use as input file for BioMercator.

Supp Mat 3. Number of QTLs per trait and per study and frequency of heterotic QTLs.

Supp Mat 4. Frequency distribution of the number of QTLs based on proportion of phenotypic variance explained (PVE).

Supp Mat 5. Relationship between number of detected QTLs and population size (expressed as number of progenies) for GY (solid circles) and grain yield component traits (empty circles).

Supp Mat 6. Mean values of Proportion of Variance Explained (PVE) of QTLs computed per chromosome intervals of $20 \mathrm{cM}$.

Supp Mat 7. Detailed results of MQTL analysis.

Supp Mat 8. Comparison of common MQTL positions detected in the present study and those from Wang et al. [20]. 